\section{DOC NOMADS, AO-NORTE and ESE: A Project of Cinema and Education at Viana do Castelo Polytechnic}

\section{Abstract}

There is a broad consensus on the recognition of cinema as a means of acquiring media literacy. The problematization of cinema as an artistic expression and the promotion of interdisciplinarity between the areas of communication, cinema and education and artistic education in particular that have been established in the field of communication science teaching. In this context, the purpose of this article is to describe an action-research that is repeated annually, when students are confronted with cinema, audio-visual language, analysis of still and moving images, the follow-up of documentary creation with students from a cinema course and the dynamization of an audio-visual space from the text of a Portuguese writer, Almada Negreiros "Manifesto Anti Dantas". The findings provide useful information on the contribution critical analysis strategies bring to art in general and cinema in particular and that the study of visual culture in terms of economy, business, technology, experiences provide a more critical understanding of society through projects that guarantee a free and flexible teaching-learning program and stimulate much discussion and polemic.

Keywords: Cinema; Education; Young

Received: September 11, 2018; Accepted: October 29, 2018; Published: November 02,2018

\section{Introduction}

This article aims to present contributions for reflection on the cultural formation of students of higher education, having as reference what is considered by us as the basic for the discussion of cinema and education in contemporary teaching. So, we present the theories [1-6]. Finally, we also present a position regarding the insertion of cinema in the higher education students' training, regardless scientific areas in which they are enrolled. In this context, we diagnose students' previous ideas when they begin a basic training in cinematographic language, supported by film and audiovisual specialists, the AO-NORTE cineclub, longstanding partners of the ESE-IPVC. We describe an action-research that is repeated annually, when students are confronted with cinema, audiovisual language, analysis of still and moving images, the accompaniment of the creation of documentaries with students from a film course, and the dynamization of an audiovisual space from the text of Almada Negreiros entitled "Manifesto Anti Dantas".

\section{Anabela Moura ${ }^{1 *}$, Carlos Almeida ${ }^{1}$ and Raquel Pacheco ${ }^{2}$}

1 School of Higher Education (ESE), Polytechnic Institute of Viana do Castelo (IPVC), Portugal

2 Center for Research in Arts and Communication (CIAC), University of Algarve, Portugal

*Corresponding author: Anabela Moura

झ amoura@ese.ipvc.pt

School of Higher Education (ESE), Polytechnic Institute of Viana do Castelo (IPVC), Portugal.

Tel: +351258 809610

Citation: Moura A, Almeida C, Pacheco R (2018) DOC NOMADS, AO-NORTE and ESE: A Project of Cinema and Education at Viana do Castelo Polytechnic. Ann Behav Sci Vol. 4 No. 2:5

\section{Cinema as a pedagogical language}

In a time when the images that are given to us from the world tend to confuse our gaze, reflecting on image and sound is not a superfluous activity. Andre [7] saw the cinema as "an open window to the world", mainstream cinema has been manifesting a strong tendency to become a videogame on a large screen while the television screen increasingly takes the form of a lock, that is, the visual tends to take the images place. We live in a culture saturated with audio-visual stimuli, consumers of still and moving images, young people (and also children and adults) are constantly in contact with videos, photographs, as well as the digital devices that allow them to be producers and disseminators of all of the produced material [8].

Theorists have always tried to explain this enchantment of the human being by the cinema. Morin [1] considers that cinema is like the dream and the human imagination that can awaken and reveal shameful and secret identifications, which he calls a 
phenomenon of projection-identification, where the spectator tends to incorporate in himself the characters of the screen thanks to physical and moral similarities that he finds in them. In this way the cinema "brings a way relating images, subjects, discourses, objects, narratives that transfigure, so to speak, other spaces and relations" [3]. Humans construct images from the earliest days of life.

Reading images, however, as an intrinsic process from the external stimulation, is a competence forced on a story of its own. And some authors, like Jean Piaget, have demonstrated that it is a competence that develops in parallel with the acquisition and mastery of verbal language, both (image decoding and linguistic coding) participating in and of the process of intelligence [4].

Machado [9] believes that the myth of the cave, celebrated by Plato, described for the first time what would be the cinema. In the allegory of the Greek philosopher, the wall fulfills the role of the screen, the flame replaces the projector and the sculptures, created by illusionist artisans, are what today is film or film support.

Cinema is the basis of the audiovisual [5], the cinematograph built at the end of the $19^{\text {th }}$ century by the Lumière brothers was the forerunner of all this audiovisual panoply which we have access through the new technologies in the days that follow. When cinema comes out of the dark room, it is no longer only displayed on the big screen, it "multiplies in forms and devices that the visual arts are constantly renewing: Multiple screens, mobile projectors, spectators' interventions" [3]

The reading of images and the understanding of the visual culture continues to be increasingly the object of study of researchers and educators of all scientific areas, who state that "almost everything of the little that we know, in relation to the produced knowledge, arrives to us by the means of communication and information. These, in turn, also construct images of the world. Images to delight, to entertain, to sell, with messages about what we should wear, eat, pretend, think" [10]. This argument, used in an article written for 12 years, warns of the need for visual literacy, which is expressed in various names such as reading the image and critical understanding of visual culture.

This and many other articles, research projects and research at masters and doctoral level, point to the need to use theoretical frameworks in the fields of arts, education, anthropology, sociology, history, science and technology (virtual reality, artificial intelligence, robotics, nanotechnology, biological engineering, artificial life, genetic engineering, the internet, and others) and communication. We can't ignore the role that technology has in transmitting knowledge in education in general and specifically in arts education [6], enabling new paths for creative forms and promoting incentives for permanent innovation.

Cinema, mainly in France, has a pedagogical tradition as a language [11] and arises along with the appearance of film clubs or cinema clubs. If, on the one hand, they often sinned by taking a film approach as an almost unattainable "work of art," giving too much emphasis on content, on the other they allowed informal discussions and approaches trying to understand them within their sociopolitical and artistic contexts. The cine club was the first way of film education and has until today a prominent role in this field, mostly through the socio-educational side, developing several numbers of projects, such as socio-cultural projects, pedagogical, social projects, with the community and different institutions giving emphasis on the work of sensitization and education to the cinema.

The relationship between cinema and education was historically marked by didactic practices, especially in the school context, which used cinema as an audiovisual resource. The films have long been used in the classroom as common pedagogical resources that illustrate or deepen certain subjects that are part of the school curriculum. With the formative potential that cinema has, its use is inevitable as this type of resource.

\section{Research and Methods}

\section{DOC NOMADS, AO-NORTE and ESE}

In the first semester of the academic year 2017/18, in addition to the 3rd edition of the DOC NOMADS of the Master Course of the Lusófona University of Lisbon, literature and film appear as a challenge of the new project launched by Ao-Norte (Association of Production and Audiovisual Animation), to the Higher School of Education of Viana do Castelo, where yearly students of various degrees in the field of arts have the opportunity to hear, see, think and talk about cinema. DOC NOMADS is the first joint master's degree in Europe in the field of documentary film production and study. Being a two-year international postgraduate program it is run by European universities from three countries: Portugal, Hungary and Belgium. Ao-Norte is a non-governmental organization (NGO), a non-profit audiovisual production and animation association, founded in 1994, headquartered in Viana do Castelo, Portugal. This association has the purpose of audiovisual production and dissemination, as well as cooperation in the development of different areas, such as teaching, education and culture. Ao-Norte is also a member of the Portuguese Federation of Cine clubs and develops projects in the area of cinema and education in Portugal, such as: Look at the Real; Stories in the Square; Video in the School; Meetings of Cinema at Viana; among others. As for the European level, it develops projects such as: YEFF - Young European Film Forum for Cultural Diversity; YEAD - Young European (Cultural) Audience Development; ICCI Network-Images of Culture/Image Culture. And now it also has partnerships in Africa and Brazil. Like AoNorte, the Viana do Castelo Higher School of Education (Teacher Training College) at Viana do Castelo Polytechnic, is constantly open to develop new and attractive projects. Developing an ancient and profitable partnership with Ao-Norte and with a great passion for cinema, the Higher School of Education, does not measure efforts to connect cinema, education and arts within this synergy. This year the project was entitled "Cine-PoetryLiterature and Cinema" and was introduced to the new students as an artistic space and privileged place of aesthetic enjoyment and identity development.

We believe that such an experience would provide learning from the interpretation of a text and would develop creativity, from building each student individuality, fostering increased confidence in one's personal capacities. We also knew that for future Arts 
and Culture Management specialists and Art and Technology technicians such a project would contribute to an enrichment of their communication and intercultural skills, since it would involve interaction between students, in a systematic exchange of ideas, beliefs and symbolic values. Gardner [12] States that the human being is able to create symbolic entities in order to convey codes of meaning so that their peers can understand, interpret, recognize, criticize or transform themselves in a given context. $\mathrm{He}$ also points out that the question of symbols is directly linked to culture, for our construction of the reality is based on the availability of a wide range of mental conceptions or symbolic forms. Individuals' efforts to capture their experiences and express them in a way that can communicate effectively depend on a combination of these conceptions or symbolic forms that convey emotional states. The human being lives in a symbolic universe and has a basic and intense need to create meanings and invest in the world, trying to find meanings everywhere and transform experience constantly to discover new meanings. This will enable artists, film makers, and teachers to systematically create new symbols that will generate different readings.

The methodology adopted in this study was that of actionresearch previously mentioned, with the teams formed by students, professors of two institutions of Higher Education and a trainer of a Cultural Association, with protocol of collaboration with one of the Institutions: Universidade Lusófona de Lisboa (ULL) and the Higher School of Education at Viana do Castelo Polytechnic Institute and Ao-Norte, covering students between the ages of 18 and 40 years.

\section{Methodology}

A qualitative method was selected as it was considered more appropriate than other qualitative methods because of its emphasis on solving educational problems diagnosed in specific situations. There are other reasons why we chose this research method.

\section{Participatory.}

2. It promotes social change.

3. Contributes to the knowledge and personal understanding of educators.

4. Methodology that stimulates curricular innovation.

5. Potential to work on a theoretical model of curricular reorganization with students.

Data collection took place through:

1. Realization of 3 documentaries and 9 videos (performances produced by students).

2. Contents (teachers/trainer from Ao-Norte).

3. Classroom photos.

4. Field Notes, which included informal talks with students.

5. Written and oral reflections.

\section{Subjects and context of the study}

DOCNOMADS and Cinepoesia (Cine-Poetry) were two action- research projects that aimed to implement collaborative practices among professors, students of Arts and Cultural Management BA and Art and Technology (Light, Sound and Image) Professional Degree and film experts from Ao- Norte and Lusófona University, to promote innovative performances of students in the Art and Technology sector. The key questions that were addressed in the design of this action research were:

(i) Will the use of image analysis strategies allow Arts students to develop their motivation for film and photography?

(ii) Will this scientific-didactic knowledge facilitate the development of cultural, communication and professional skills of the future professionals of Arts?

\section{Sample}

The following students and teachers collaborated in both Projects (Table 1).

At the end of October, beginning of November, the students of the Lusofona University Master's Degree - DOCNOMADS, returned to the ESE-IPVC for the $3^{\text {rd }}$ time, and this time they brought 6 colleagues from the Sound Degree. Along with 13 Arts and Cultural Management students at Higher School of Education +2 of ERASMUS of Valencia and the 23 students of the Professional Arts and Technologies Degree (Light, Sound and Image), they produced three documentaries related to the following themes: Twilight to night, night to twilight; Underground; and Ocean.

When confronted with a module related to media education and image education, students always react with a certain mistrust. Firstly, they do not understand the interest that such a confrontation might have for their formation as professionals of basic education, light, sound and image, or future artistic and cultural management sector. At the end of the training, which usually runs between 4 and 6/7 weeks, they show enthusiasm and very different perceptions, although they feel the experiences differently, as the examples presented here will confirm.

The experience I took from the Docnomads project was little or nothing, that is, it was a disappointment due to the lack of cooperation on the part of foreign students in sharing their ideas and even requiring assistance (3rd year Arts and Cultural Management's student).

Another student stated the following regarding the same project: This project is very important in my view, because we had the possibility to work with different people and cultures, which ends up making our professional and personal growth more and more comprehensive. Regarding the activity of the Docnomads I participated in all sessions, namely in the session of reception to the students and in the final session, for the visualization of the final videos projected at Verde Viana cinema (3rd year Arts and Cultural Management's student).

The Cine-poetry project provided the articulation of literature and cinema in the classes of Show Production at the Arts and Technologies Professional Superior Course and Work Placement I of the Art and Cultural Management BA, and made those students aware of artistic values that dialogue and interacted with culture through the symbolic and allegorical dimensions of literary and cinematographic languages. This experience allowed students 
Table 1 Participant students and teachers.

\begin{tabular}{|c|c|c|c|c|}
\hline Lusófona University & Lusófona University & \multicolumn{3}{|c|}{ Higher school of education at IPVC } \\
\hline Masters on Cinema & Sound Degree & $\begin{array}{c}\text { Artistic and Cultural } \\
\text { Management BA Degree }\end{array}$ & ERASMUS students & $\begin{array}{l}\text { Professional Art and } \\
\text { Technology Degree }\end{array}$ \\
\hline 19 students & 6 students & 13 students & 2 students & 23 students \\
\hline 2 teachers & 2 teachers & $\begin{array}{c}1 \text { teacher and } 1 \text { Ao-Norte } \\
\text { trainer }\end{array}$ & $\begin{array}{c}1 \text { teacher and } 1 \text { Ao-Norte } \\
\text { trainer }\end{array}$ & $\begin{array}{c}1 \text { teacher and } 1 \text { Ao-Norte } \\
\text { trainer }\end{array}$ \\
\hline Docnomads Project & Docnomads Project & Docnomads Project & Docnomads Project & Docnomads Project \\
\hline-- & -- & Cine-poetry Project & Cine-poetry Project & Cine-poetry Project \\
\hline
\end{tabular}

to reflect on the metaphorical meshes of a literary text through the metaphors of cinematic language and codes of meaning. This pedagogical project supported by Ao-Norte approached the poetic text and provided a space for audiovisual creation (Figure 1).

The students were confronted with cinema, audiovisual language, analysis of still and moving images, after having created documentaries with DOCNOMADS students.

Having analysed and interpreted Almada Negreiros text"Manifesto Anti Dantas", one of the Arts and Technology students said, it was the presentation that stood out the most, it was very interactive, and in a short time and in a few words, we were able to explain, open and think better about life. That not everything appears from nothing, that everything has a methodology. Showing us various types of works of art, with the intention of knowing how to appreciate and develop our ability to interpret. This way we realized that each work had a different story, and each one can have different points of view, making the presentation funnier. The works also made us think and reflect, they communicate with us, we are curious to see why each character was painted in the first or last plane, why a light should emerge in a character, and many more techniques that we think are irrelevant, but in the end we realized that whoever did it was a genius and had so much imagination that it gave life to the work. I realized that without light there is no image, which makes us think a lot, that the world was not made by chance, like works of art, even the world itself has its history. As the world evolves the image too, and today to get a video, we start from the image, which by itself, has developed by the light, and we are always evolving without limits.

An art and cultural management student noted the following:

- The sessions of Cine-Poetry were one of the most interesting and stimulating activities of this semester. I was present in all the sessions and in the recordings and I collaborated not only with my group, but also with the groups of my colleagues.

- The words that were associated to the excerpts of the text distributed to each of the five groups led the students to the selection of spaces and props, construction of characters (physical presence, facial expression, gestures, movements, sound elements) and through body expression they reinterpreted the Almada's words (Figure 2 ).

- The idea will be backlit, we plan to record our videoperformance in the Higher School at the dance and drama room. Face to face, I and SM will attack each other, while
$\mathrm{CL}$ throws objects at us, until one falls to the floor, thus transmitting all the anger and revolt that Almada Negreiros felt to his 23 years when he wrote this text, represented by the action of throwing objects at a portrait of someone. The reason for not being chosen a specific character, is related to the fact that we can give the public the opportunity to be him to choose 'his Julius Dantas', and we all feel that there is a Dantas that prevents us from do what we want.

Another art and technology student mentioned in his report: At the end of image analysis exercises, we were able to explain, open and think better about life. That not everything appears from nothing, that everything has a methodology. Showing us various types of works of art, with the intention of knowing how to appreciate and develop our ability to interpretation with this module on visual culture I improved my technical knowledge of the image, because now I am more aware of what to do and think how I will do.

\section{Results and Findings}

Cinema and education as part of media education [5], were the teaching learning strategies considered as fundamental for acquiring a complete media literacy and that education for the media is to know their contexts, their cultures and languages so to combine technologies and these same languages. The interdisciplinary curriculum and image analysis and education strategies for the media used as pedagogical methodology in this project were considered appropriate for use in the context of both courses. However, we believe that students would need a more extensive professional preparation not only in art, but also education for the media. The strategies of analysis, and production of images were considered adequate for the development of cultural, aesthetic, artistic and technological competences of the students. The use of literature in its various aspects, from the literature of oral tradition to the interaction of text and image, was an effective stimulus that allowed increasing the capacity of reading visual images by the students and consequent extension of their understanding about the society in which they live.

The development of the literacy in these two projects consisted on developing understanding of the meaning of art in context, and particularly but not exclusively, concerned itself with the role that language can play in making accessible at various levels of understanding and complexity.

This action research allowed us to verify that critical analysis strategies encourage significant discussion about art in general and cinema in particular and that they are symbolic 


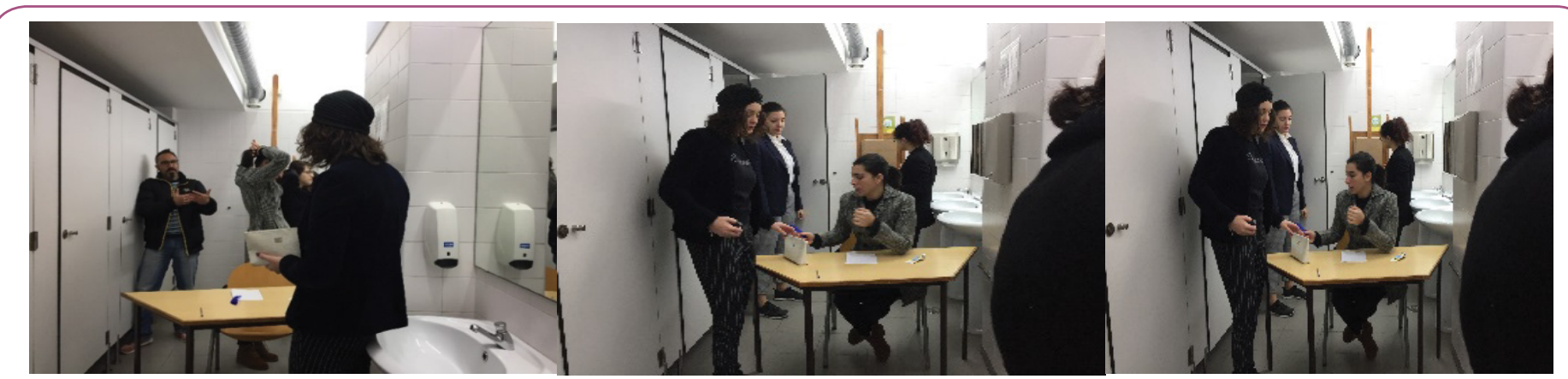

Figure 1 Creation/Interpretation@ Farsa de Inês Pereira.

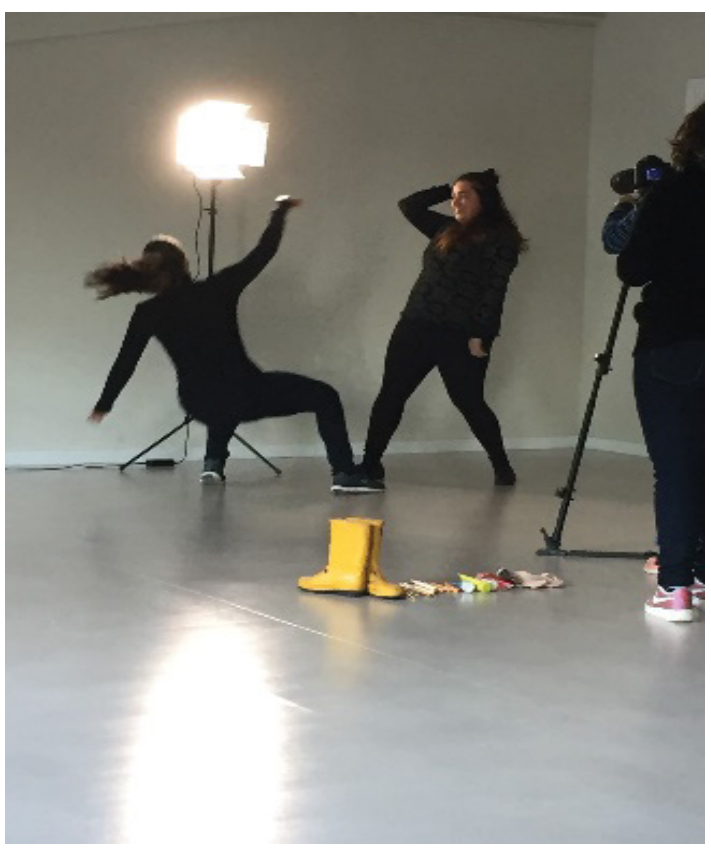

Figure 2 Interpretation (C) Anabela Moura.

representations of diverse realities and that the study of visual culture in terms of economy, business, technology, experiences provide a more critical understanding of society [13].

\section{Final considerations}

Among a number of aspects that have been mentioned previously, we intend to highlight some of those that we believe may provide future guidelines:

1. The strategies of analysis and production of images allow students to develop their motivation to increase their perceptual, historical and critical skills and understanding of social and cultural issues.

2. The construction/appropriation of this scientific-didactic knowledge during the 1st semester facilitate the development of cultural, communication and professional skills of the students.

3. Teachers need to examine their curricular interventions and reflect how images can be used as part of the general training of students, or as part of specific courses.
4. Cinema as an important language in the pedagogical process.

\section{Discussion}

Observation of the participants during the projects and their reflections and evaluations suggest that the objectives that were devised for this action research were attained in the short term. We believe that this experience has provided the learning of the interpretation of life (case of the Docnomads) and of a text (Cine-poetry) and developed the creativity from the construction of the individuality of students, increased their confidence in their personal capacities. Cine-poetry provided the articulation of literature and cinema in the classes of Show Production of Spectacle of the Professional Higher Course of Art and Technologies and of Work Placement I of the Art and Cultural Management BA and made the students aware of artistic values that dialogue and are in interaction with culture, through symbolic and allegorical dimensions of literary and cinematographic languages.

Such experiences made students aware of technological changes that are developing in parallel with social, economic and political transformations. New languages emerge, directed towards a cyberculture, where unprecedent premises are discussed, and new perspectives are opened for different areas of knowledge. We realize that technology alone does not promote change, it needs to be associated with projects that develop their critical, creative aspects, connecting technology to the arts, promoting an education without boundaries or limits. We underline the urgency of working with young people also on the less positive aspects of the media and new technologies that often, when used as tools of the system, treat them as mere consumers, using less noble strategies such as manipulation.

We are aware that, for future managers of the sectors of Arts and Culture and for the future professionals of Performative Arts, these projects help to enrich their communication, artistic and intercultural skills, as they imply interaction between people, in a systematic exchange of ideas, beliefs and values. Such projects guarantee a free and flexible teaching-learning program and stimulate much discussion and polemic. Many educators around the world have been pointing out that the training of students has been weighted heavily on the side of their producing practical work to the detriment of examining content and meaning $[14,15]$.

\section{Conclusion}

It should be emphasized that all this implies a necessary 
adaptation of curricula and methodologies, where learning shall not be limited to the mere acquisition of some knowledge but also shall involve the development of processes that imply new knowledge and professional skills in specific and multidisciplinary

\section{References}

1 Morin E (1997) The cinema or the imaginary man. Lisbon: Clock of Water.

2 Bergala A (2008) A hypothesis cinema: Small treatise on the transmission of cinema. Rio de Janeiro: Booklink.

3 Migliorin C (2015) Inevitably Cinema: Education, politics and mafua. Rio de Janeiro: Alley of Azougue.

4 Lobo G (1999) Public training for cinema. Master's Dissertation in Cultural Management, University of Algarve, Portugal.

5 Pacheco R (2009) Young people, media and stereotypes. Field diary at a problem school. Lisbon: Horizon Books.

6 Moura A, Barbosa G, Almeida C (2017) Cinema in Higher Education Languages in Approximation. J Edu Society Behav Sci 21: 1-11.

7 Andre B (1992) What is cinema? Lisbon: Horizon Books. fields [6]. These tools also strongly influence students' creative responses, so a professional attitude to curriculum development should draw from and build upon the extensive work already carried out in this field and teachers should renew their teaching content and the strategies they use to reach their students.

8 Moura A, Cachadinha M, Almeida C (2017) Cinema Integrated Learning in Higher Education - the Case of Viana do Castelo Polytechnic - Northern Portugal. J Edu Social Pol 4: 143-151.

9 Machado A (2005) Pre-cinemas and post cinemas. Campinas: Papyrus.

10 Sardelich ME (2006) Reading of images and visual culture: Unraveling concepts for the educational practice, In Educar, (27) Curitiba: Editora UFPR pp: 203-219.

11 Bergala A (2008) A hypothesis cinema: Small treatise on the transmission of cinema. Rio de Janeiro: Book link.

12 Gardner H (1987) Art, mind and brain: A cognitive approach to creativity. Buenos Aires: Paidos.

13 Hernandez F (2006) Visual culture, educational change and project work. Porto Alegre: Artmed.

14 Allison B (1988) Art in context. J Art Design Edu 7: 2.

15 Allison B (1974) Professional art education?. J NSAED 1: 3-9. 